\title{
Preliminary evidence of the presence of lymphatic vessels immunoreactive for D2-40 and Prox-1 in human pterygium
}

\author{
ANCA MARIA CIMPEAN ${ }^{1}$, MIHAI POENARU SAVA ${ }^{2}$, MARIUS RAICA $^{1}$ and DOMENICO RIBATTI ${ }^{3}$ \\ ${ }^{1}$ Departments of Histology and ${ }^{2}$ Ophthalmology, 'Victor Babeş' University of Medicine and Pharmacy, Timisoara, \\ Romania; ${ }^{3}$ Department of Human Anatomy and Histology, School of Medicine, University of Bari, Bari, Italy
}

Received February 24, 2011; Accepted April 27, 2011

DOI: 10.3892/or.2011.1342

\begin{abstract}
Human pterygium is a benign fibrovascular outgrowth of the corneo-conjunctival junction, characterized by tissue remodeling, cellular proliferation, angiogenesis and inflammation. No data are available concerning the presence of lymphatic vessels in this pathological condition. The aim of this study was to evaluate by immunohistochemistry, using antibodies against D2-40, Prox-1 and $\mathrm{Ki}-67$, the presence and the proliferative activity of lymphatic vessels in human pterygium. An increased lymphatic microvessel density was observed in the human pterygium compared to the normal conjunctiva. Moreover, D2-40-positive lymphatic endothelial cells were also actively proliferating, as assessed by $\mathrm{Ki}-67$ immunostaining, while in normal conjunctiva proliferating lymphatic endothelial cells were not detectable. Overall, these data clearly indicate the presence of active proliferating lymphatic vessels in human pterygium, suggesting that active lymphangiogenesis occurs in this pathological condition.
\end{abstract}

\section{Introduction}

Pterygium is a disease characterized by surface ocular lesions associated with chronic ultraviolet exposure in which the primary effect is a solar actinic elastosis within the stroma and all other changes are secondary to the primary effect (1-7). Pterygium is characterized by cellular proliferation, inflammatory infiltration, fibrosis, angiogenesis, and extracellular matrix breakdown; the lesion begins to grow from limbal epithelium and invades the cornea centripetally followed by conjuntival epithelium, exhibiting degenerative and hyperplastic changes (1-7).

Seifert and Sekundo identified intraepithelial capillaries in the optical half of $42.3 \%$ pterygia, providing the first evidence of neovascularization in this pathological condition (8). Other

Correspondence to: Professor Domenico Ribatti, Department of Human Anatomy and Histology, School of Medicine, University of Bari, Piazza G. Cesare 11, Policlinico, I-70124 Bari, Italy

E-mail: ribatti@anatomia.uniba.it

Key words: D2-40, Ki-67, lymphatic vessels, lymphangiogenesis, Prox-1, pterygium reports followed $(9,10)$ and several angiogenic cytokines, such as fibroblast growth factor-2 (FGF-2), vascular endothelial growth factor (VEGF) platelet-derived growth factor (PDGF), transforming growth factor $\beta$ (TGF- $\beta$ ), tumor necrosis factor $\alpha$ (TNF- $\alpha$ ), interleukin- 6 and -8 (IL-6 and IL-8) and nerve growth factor (NGF) (11-14) have been implicated as mediators of angiogenesis. Furthermore, the presence of mast cells has been correlated with the degree of angiogenesis in pterygium $(15,16)$.

Several antiangiogenic approaches have been proposed for the treatment of petrygium. One case report documented the successful treatment of an early recurrent pterygium using interferon $\alpha 2 \beta$ (17) and more recently, bevacizumab, a human monoclonal antibody anti-VEGF, has been proposed in the treatment of pterygium (18-23).

Few data are available concerning lymphangiogenesis in the cornea and the presence of lymphatic vessels in pterygium (24). The aim of this study was to evaluate by immunohistochemistry, by using antibodies against D2-40 and Prox-1, the presence of lymphatic vessels in human pterygium.

\section{Materials and methods}

The study group included 20 bioptic specimens of surgical excised primary or recurrent pterygium. Ten nasal epibulbar conjunctival segments, excised during cataract surgery near the limbus, were used as control tissues. Specimens were fixed in buffered formalin for $48 \mathrm{~h}$, embedded in paraffin, and $5 \mu \mathrm{m}$ sections were stained with hematoxylin-eosin for routine diagnosis.

Lymphatic vessels were immunostained with a monoclonal antibody against D2-40 as a cytoplasmatic marker (purcahsed from Dako, Carpinteria, USA) and a polyclonal anti-Prox-1 antibody as a nuclear marker (dilution 1:200; $2 \mathrm{~h}$ incubation at room temperature; code 11941 from Abcam, UK) by using an avidin-biotin-peroxidase method. Lymphatic endothelial cell proliferation was assessed using a Ki-67 antibody (clone MIB1; Dako) by incubating for $30 \mathrm{~min}$ at room temperature). The markers were detected by a simple immunostaining (the final product was visualized with 3,3'-diaminobenzidine hydrochloride) or were co-localized by applying a doublestaining method using the Doublestain Envision kit (Dako). Counterstaining was performed with modified Lille's Hematoxylin. All immunohistochemical steps were performed in an 


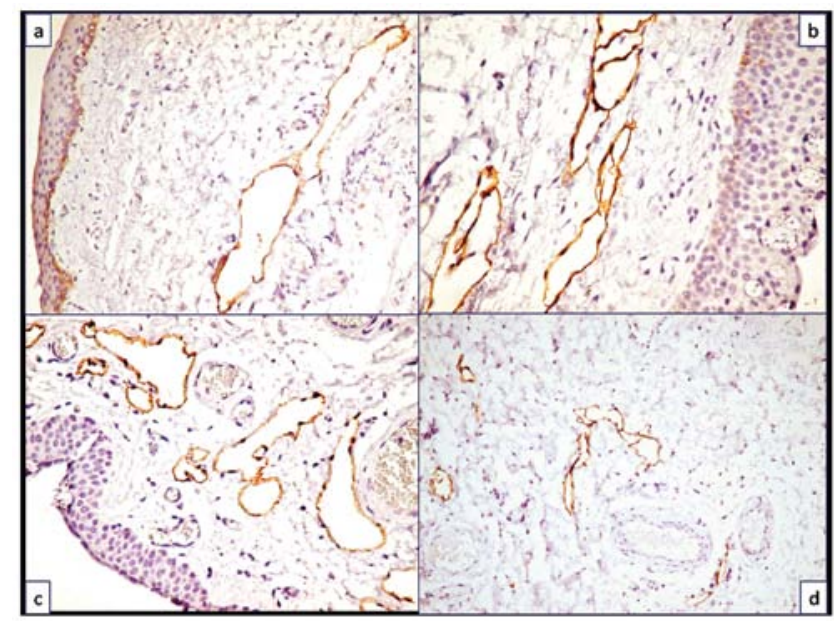

Figure 1. (a) In normal conjunctiva, basal cells are immunoreactive to D2-40 and scarce, large lymphatic vessels immunoreactive to D2-40 are observed deeply inside the stroma. Lymphatic vessels immunoreactive to D2-40 are located close to the epithelium (b and c) or deep inside the fibrous stroma (d) in human pterygium. Original magnification, x200.

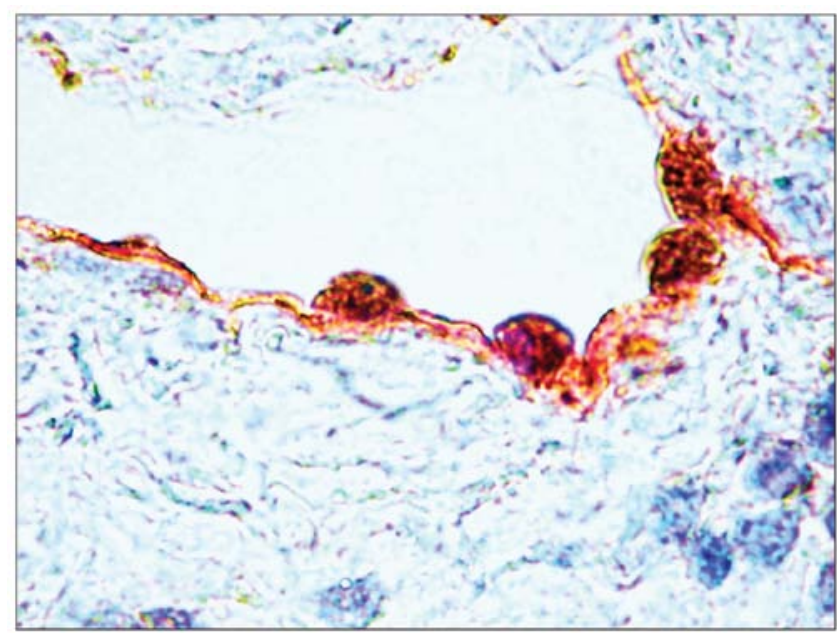

Figure 2. Intense proliferative activity assessed by Ki-67 (brown nuclear staining) along the D2-40 positive lymphatic endothelium (red, cytoplasmic reaction) in human pterygium. Original magnification, $\mathrm{x} 400$.

automated fashion with the use of PT Link for automated controlled antigen retrieval and the Dako Autostainer.

Lymphatic microvascular density (LMVD) was estimated at $\mathrm{x} 200$ magnification (covering an area of $0.74 \mathrm{~mm}^{2}$ ) by two independent observers (M.R. and A.M.C.), using the hot spot method. Microscopic images were captured in a JPEG format, and LMVD was calculated using the Nikon Lucia G program of analysis of the microscopic images (Nikon, Tokyo, Japan).

The local research ethics committee approved the protocol of the study, and informed consent was obtained from all subjects according to the World Medical Association (WMA) Declaration of Helsinki.

\section{Results}

D2-40 immunostaining specifically highlighted the lymphatic vessels in normal conjunctiva, whereas rare positive lymphatic vessels with normal morphology were observed deeply inside

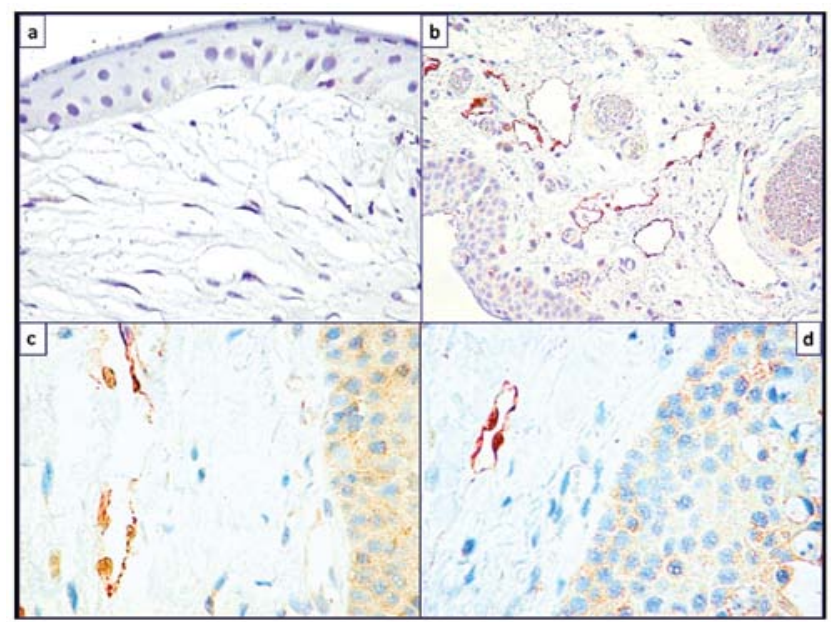

Figure 3. (a) Absence of immunoreactivity to Prox-1 in normal conjunctiva (b) Strong immunoreactivity for both D2-40 and Prox-1 in human pterygium. D2-40 red cytoplasmic immunostaining may be (c) discontinuous or (d) continuous; Prox-1 staining in the nucleus is shown in red. Original magnification, $\mathrm{x} 400$ (a, c and d), x200 (b).

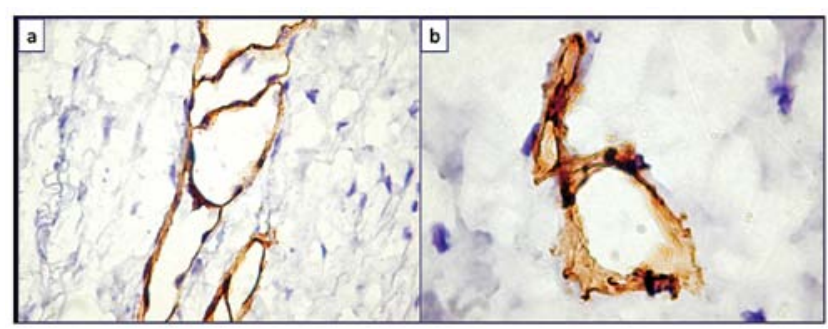

Figure 4. Lymphatic vessels in human pterygium immunoreactive to D2-40 suggestive of (a) intussusception or (b) a sprouting mechanism of newformation. Original magnification, $\mathrm{x} 400$.

the connective tissue (Fig. 1a). LMVD ranged between 1-3 vessels/field at $\mathrm{x} 200$ magnification.

In human pterygium the lymphatic vessels were distributed in close proximity of the epithelial layer, were tortuous, their lumen was highly splitted and the vascular wall was discontinuous (Fig. 1b). Most lymphatic vessels were distributed in a network-like fashion (Fig. 1c and d), while in normal conjunctiva lymphatic vessels were presented as distinctive structures, and were separated from each other by connective tissue stroma. The LMVD range was between 7-10 vessels/field at $\mathrm{x} 200$ magnification.

By means of a double immunostaining with antibodies anti D2-40 and anti-Ki-67, a high proliferative activity of lymphatic endothelial cells was detectable in human pterygium, because all D2-40-positive vessels were also positive for Ki-67 (Fig. 2), while in normal conjunctiva the proliferative activity of lymphatic endothelial cells was not detectable.

By using an antibody anti-Prox-1, a constitutive marker for lymphatic endothelium, numerous Prox-1-positive lymphatic endothelial cells or scattered fusiform stromal cells were found only in human pterygium, but not in normal conjunctiva. Many lympathic vessels with Prox-1-positive cells showed a moderate reactivity for D2-40 and a discontinuous or continuous wall (Fig. 3c and d). Morphological pictures suggestive of an 
intussusceptive (Fig. 4a) or sprouting (Fig. 4b) mechanism of lymphangiogenesis were also recognizable.

\section{Discussion}

In this study we have demonstrated the presence of lymphatic vessels immunoreactive to D2-40 and Prox-1 in human pterygium. We found a high number of lymphatics with a high proliferative activity in pterygium as compared with normal conjunctiva.

Few data are available concerning the presence of lymphatic vessels in human pterygium and lymphangiogenesis in the cornea. Seifert et al (24) by using conventional staining procedure (hematoxylin-eosin, alcian blue and toluidine blue) demonstrated the presence of many large-diameter lymphatic vessels in a markedly edematous human pterygium and more recently Pérez-Rico et al (6) showed the expression of fibulin-2 and fibulin-3 in the subepithelial connective tissue of human pterygium distributed along blood and lymphatic vessels.

In regards to lymphangiogenesis, in a mouse model of corneal induced angiogenesis and lymphangiogenesis, topical or systemic application of bevacizumab was shown to inhibit both inflammation-induced angiogenesis and lymphangiogenesis, suggesting an important role of VEGF-A in corneal lymphangiogenesis (22). Moreover, Lee et al (23) suggested that edema in conjunctivo-limbal autograft observed in patients treated with bevacizumab as adjuvant therapy might be due to a suppression of lymphangiogenesis induced by this drug.

In human pterygium, an increased number of proliferating lymphatic vessels could be the result of a compensatory mechanism to reduce edema occurring in this pathological condition. In fact, in the pathogenesis of pterygium, chronic irritation produces a chronic inflammatory cell infiltration with a consequent inflammatory edema (25). Moreover, active angiogenesis is responsible for the formation of immature, dilated and high permeable blood vessels.

\section{References}

1. Peckar CO: The aetiology and histo-pathogenesis of pterygium. A review of the literature and a hypothesis. Doc Ophthalmol 31: 141-157, 1972 .

2. Vaughan D and Ashbury T: Conjunctiva. In: General Ophthalmology. Vaughan D and Ashbury T (eds). Lange Medical Publications, Los Altos, p82, 1977.

3. Crăiţoiu S, Ciprian L, Rodica M, et al: Etiopathogenic aspects in development and evolution of pterigyum. Oftalmologia 52: 29-34, 2008 (In Romanian).

4. Duke-Elder S: Conjunctival diseases. Degenerations. In: System of Ophthalmology. Duke-Elder S (ed). Henry Kimpton, London, pp573-582, 1974.
5. Džunić B, Jovanović P, Veselinović D, et al: Analysis of pathohistological characteristics of pterygium. Bosn J Basic Med Sci 10: 307-313, 2010.

6. Pérez-Rico C, Pascual G, Sotomayor S, et al: Tropoelastin and fibulin overexpression in the subepithelial connective tissue of human pterygium. Am J Ophthalmol 151: 44-52, 2011.

7. Detorakis ET, Zaravinos A and Spandidos DA: Growth factor expression in ophthalmic pterygia and normal conjunctiva. Int J Mol Med 25: 513-516, 2010

8. Seifert $\mathrm{P}$ and Sekundo W: Capillaries in the epithelium of pterygium. Br J Ophthalmol 82: 77-81, 1998.

9. Marcovich AL, Morad Y, Sandbank J, et al: Angiogenesis in pterygium: morphometric and immunohistochemical study. Curr Eye Res 25: 17-22, 2002.

10. Aspiotis M, Tsanou E, Gorezis S, et al: Angiogenesis in pterygium: study of microvessel density, vascular endothelial growth factor, and thrombospondin-1. Eye 21: 1095-1101, 2007.

11. Kria L, Ohira A and Amemiya T: Immunohistochemical localization of basic fibroblast growth factor, platelet derived growth factor, transforming growth factor-beta and tumor necrosis factor-alpha in the pterygium. Acta Histochem 98: 195-201, 1996.

12. Lee DH, Cho HJ, Kim JT, et al: Expression of vascular endothelial growth factor and inducible nitric oxide synthase in pterygia. Cornea 20: 738-742, 2001.

13. Di Girolamo N, Kumar RK, Coroneo MT, et al: UVB-mediated induction of interleukin- 6 and -8 in pterygia and cultured human pterygium epithelial cells. Invest Ophthalmol Vis Sci 43: 3430-3437, 2002 .

14. Di Girolamo N, Wakefield D and Coroneo MT: UVB-mediated induction of cytokines and growth factors in pterygium epithelial cells involves cell surface receptors and intracellular signaling. Invest Ophthalmol Vis Sci 47: 2430-2437, 2006.

15. Ribatti D, Nico B, Maxia C, et al: Neovascularization and mast cells with tryptase activity increase simultaneously in human pterygium. J Cell Mol Med 11: 585-589, 2007.

16. Ribatti D, Nico B, Perra MT, et al: Correlation between NGF/ TrkA and microvascular density in human pterygium. Int $\mathbf{J}$ Exp Pathol 90: 615-620, 2009.

17. Esquenazi S: Treatment of early pterygium recurrence with topical administration of interferon alpha. Can J Ophthalmol 40: 185-187, 2005.

18. Hosseini H, Najabat M and Khalili MR: Bevacizumab (Avastin) as a potential adjunct in the management of pterygia. Med Hypotheses 69: 925-927, 2007.

19. Bahar I, Kaiserman I, McAllum P, et al: Subconjunctival bevacizumab injection for corneal neovascularization in recurrent pterygium. Curr Eye Res 33: 23-28, 2008.

20. Banifatemi M, Razeghinejad MR, Hosseini H, et al: Bevacizumab and ocular wound healing after primary pterygium excision. J Ocul Pharmacol Ther 27: 17-21, 2011.

21. Fallah Tafti MR, Khosravifard K, Mohammadpour M, et al: Efficacy of intralesional bevacizumab injection in decreasing pterygium size. Cornea 30: 127-129, 2011.

22. Bock F, Onderka J, Dietrich T, et al: Bevacizumab as a potent inhibitor of inflammatory corneal angiogenesis and lymphangiogenesis. Invest Ophthalmol Vis Sci 48: 2545-2552, 2007.

23. Lee JW, Park WY, Kim TI, et al: Clinical results after application of bevacizumab in recurrent pterygium. J Korean Ophthalmol Soc 49: 1901-1909, 2008.

24. Seifert P, Eckert J and Spitznas M: Topological-histological investigation of the pterygium. Graefes Arch Clin Exp Ophthalmol 239: 288-293, 2001.

25. Hill JC and Maske R: Pathogenesis of pterygium. Eye 13: 218-226, 1989. 